\title{
Variation for Fruit Morphological Characteristics in a Capsicum chinense Jacq. Germplasm Collection
}

\author{
Robert Lawrence Jarret ${ }^{1}$ \\ U.S. Department of Agriculture, Agricultural Research Service, Plant \\ Genetic Resources, 1109 Experiment Street, Griffin, GA 30223 \\ Terry Berke \\ Seminis Vegetable Seeds, 37437 State Highway 16, Woodland, CA 95695
}

Additional index words. habanero, fruit morphology, distributions, taxonomy, evolution

\begin{abstract}
Mature fruit of 330 accessions of Capsicum chinense Jacq. from the USDA/ARS Capsicum germplasm collection were characterized for fruit length, width, weight, and color. Mean fruit length was determined to be $47 \mathrm{~mm}$ with a range from $7.9 \mathrm{~mm}$ to 113.7 mm. Mean fruit width was $21.17 \mathrm{~mm}$ with a range of $6.18 \mathrm{~mm}$ to $40.0 \mathrm{~mm}$. Mean fruit weight was $6.31 \mathrm{~g}$ with a range of $0.18 \mathrm{~g}$ to $22.7 \mathrm{~g}$. Distributions of all characteristics were positively skewed. Distributions of fruit length, fruit weight, and fruit length/width failed the Kolmogorov-Smirnov test for normality. The distribution for fruit width was normal. Ninety-two percent of the accessions examined were elongate. Mature fruit colors included red, orange, yellow, brown (chocolate), and cream. The germplasm collection contained primarily pendent larger-fruited cultivated forms of the species, but also contained upright small-fruited primitive and semipendent transitional forms. These data define the variability for mature fruit characteristics within this germplasm collection and provide a baseline against which future introductions/acquisitions can be compared. Additional sampling of the gene pool might be expected to substantially enhance the genetic variability within the primitive forms of this species.
\end{abstract}

Fruit of members of the genus Capsicum play a major nutritional role in many cultures by serving as a source of vitamin C (Eshbaugh, 1976) and other phytonutrients (DeWitt and Bosland, 1996). The pungency associated with many forms of Capsicum makes the fresh or dried fruit a desirable spice, and many medicinal properties have been attributed to capsaicin and its analogs (Stewart et al., 2005). Although most consumers in the United States are familiar with the common sweet Bell pepper (C. annuum), the pungent jalapeno (C. annuum), and Tabasco (Mcllhenny Co., Avery Island, LA) sauce (C. frutescens), the genus Capsicum actually contains five cultivated species, each with a variety of forms, few of which are seen frequently in the U.S. marketplace. The genus also contains numerous wild species (Hunziker, 2001), several of which have only recently been described (Barboza and Bianchetti, 2005).

The cultivated species of Capsicum include $C$. annuum, C. baccatum, $C$. frutescens, C. pubescens, and C. chinense (Heiser and Pickersgill, 1969; Smith and Heiser, 1957). Of these, Capsicum chinense, often referred to as habanero, was the last to be recognized as a cultivated taxa in the modern scientific literature. Described as early as 1768 as C. angulosum (DeWitt and Bosland,

Received for publication 22 May 2007. Accepted for publication 7 Aug. 2007.

${ }^{1}$ To whom reprint requests should be addressed; e-mail Bob.Jarret@ars.usda.gov
1996), Smith and Heiser (1957) were the first to recognize its ( $C$. sinensis Jacq.) cultivated status. The presence of a calyx constriction is regarded as the species' defining characteristic and the one used to differentiate it from C. frutescens, its nearest relative (Eshbaugh, 1976). Capsicum chinense can be separated from C. annuum on the basis of the number of pedicels/node: one in C. annuum and three to five in $C$. chinense. Capsicum chinense is typically described as having rugose leaves, a dull white or waxy green corolla, and wavy seed margins (Smith and Heiser, 1957).

The full potential of C. chinense as a food crop in the United States has not been realized. Eshbaugh (1976) observed that $C$. chinense rivaled $C$. annuum as a crop in parts of South America and the Caribbean. DeWitt and Bosland (1996) referred to C. chinense as the most important cultivated pepper in South America east of the Andes. DeWitt and Bosland (1996) also noted the importance of C. chinense in the Caribbean where fruit of the species was generally referred to as habanero, Scotch Bonnet, or goat pepper. Numerous landraces with specifically adapted fruit types were widely cultivated. In the eastern Caribbean, these landraces were referred to as Congo peppers (Trinidad) or boney peppers (Trinidad). In the western Caribbean, they were referred to as Scotch bonnets (Jamaica), rocotillos (Puerto Rico), and cachucha (Cuba). Fruit of all forms of $C$. chinense are generally assumed to be quite pungent. However, pungency within this species, like within other species of Capsi- cum, varies widely (D'Arcy and Eshbaugh, 1974; DeWitt and Bosland, 1996; Tewksbury et al., 2006). Recent molecular studies have used $C$. chinense to elucidate the biochemistry and the biology of capsaicin synthesis (Stewart et al., 2005).

Capsicum chinense appears to have its origins in the western Amazon River basin (McLeod et al., 1983) and domesticated forms appear in early agricultural sites in coastal Peru (Davenport, 1970). The oldest known $C$. chinense is a 6500-year-old intact pod found in Guitarrero Cave in Peru (DeWitt and Bosland, 1996). According to McLeod et al. (1983), the range of C. chinense extends throughout central South America, the Caribbean, and into Central America. Heiser (1976) noted the prevalence of $C$. chinense in moister habitats in the lowland tropical areas in Brazil. The species is also cultivated from Mexico and the Caribbean south to and including Peru and Bolivia (D'Arcy and Eshbaugh, 1974; Pickersgill, 1971), in Jamaica (Bosland et al., 1996), and in the West Indes (Pickersgill et al., 1979).

The unique botanical characteristics of C. chinense and the basis for its taxonomic classification are well documented (Smith and Heiser, 1957). However, other than the photographs of $C$. chinense fruit provided by DeWitt and Bosland (1996), the literature contains little if any information on the range of fruit morphological characteristics present in this species. Pickersgill et al. (1979) used numerous morphologically distinct forms of C. chinense in a study to examine phylogenetic relationships within and among the cultivated taxa. However, descriptions of individual morphotypes, seed sources, or photographs were not provided. The current study was undertaken to examine and document the morphological variation present in fruit of accessions of $C$. chinense in the USDA/ARS Capsicum germplasm collection (Jarret et al., 1990).

\section{Materials and Methods}

Seed of a total of 360 accessions, identified in the Griffin genebank inventory as C. chinense, were sown in the greenhouse in May 2005 in Woodland, CA. Of these materials, 330 were determined (based on visual evaluation in the field) to be $C$. chinense, the remainder (30) being reclassified as either $C$. annuum or $C$. frutescens. The accessions of $C$. chinense represented germplasm originally acquired from Argentina (one), Belize (two), Bolivia (22), Brazil (44), Chile (one), China (one), Colombia (24), Costa Rica (17), Cuba (one), Ecuador (21), Guyana (three), Honduras (one), India (two), Mexico (23), Panama (one), Peru (11), Philippines (one), Puerto Rico (10), Salvador (one), Spain (one), Suriname (nine), Tanzania (two), Trinidad and Tobago (three), the Untied States (13), Venezuela (nine), and Zambia (one). Seedlings were transplanted to the field 5 to 6 weeks after emergence into rows $\approx 2 \mathrm{~m}$ apart ( $0.25 \mathrm{~m}$ between plants within rows). Plants 
received fertilization, irrigation, weed, and pest control measures, as required.

Fruit descriptive data were recorded using a modified (in-house) form of the IPGRI (1995) descriptor list. Fruit of each genotype were harvested at full maturity and shipped to Griffin, GA, where they were weighed, measured, and photographed. Data on fruit length, fruit width, and fruit weight were recorded on 25 randomly selected sound fruit. In those cases in which accessions contained mixtures of two or more fruit types, data were taken only on the predominant type. Values for each characteristic were averaged within accessions and these means further analyzed (Stuart and Ord, 1987). A list of descriptors, descriptor data, and digital images of the fruit of the accessions used in this study can be viewed at www.ars-grin. gov/npgs/acc/acc_queries.html. A spreadsheet containing the data set used in the analysis is available from the authors.

\section{Results and Discussion}

Although the identification of $C$. chinense can be problematic (Davenport, 1970; Eshbaugh, 1976; Pickersgill, 1966, 1971), we feel confident that the materials examined were $C$. chinense based on the clear presence of a calyx constriction. However, we acknowledge that accessions that have been previously referred to in the literature as "chili chocolate" (Pickersgill et al., 1979) are somewhat atypical. The USDA/ARS germplasm collection contained 29 accessions that were classified as (or containing predominantly) the chili chocolate phenotype. Accessions with a chili chocolate phenotype included PI nos. 159236, 159246, 215736, 257171, 257284, 260532, 281319, 281441, 281442, 315010, 315011, 315012, $315014,315015,315017,315018,315021$, 439438, 439440, 439446, 439451, 439441, 439445, 439448, 439449, 639655, and 640894 and Griffin Inventory (Grif) nos. 9269 and 9275 . The majority of these materials were originally acquired by Dr. Paul Smith (formerly of the University of California) and were collected in Chile (one), Peru (22), Spain (one), Trinidad and Tobago (one), the United States (two), and Venezuela (two).

Pickersgill et al. (1979) noted that the chili chocolate phenotype could not be referred satisfactorily as either domesticated $C$. annuum or domesticated $C$. chinense. We observed that accessions of chili chocolate had a plant growth habit and general appearance that resembled $C$. annuum in some respects and that plants and fruits were quite uniform across accessions regardless of origin. Stems and leaves of many, but not all, chili chocolate accessions were noticeably pubescent. Leaves were typically not rugose. Mean $( \pm \mathrm{SD})$ fruit length, width, and weight across all 29 chili chocolate phenotypes were $61.5 \mathrm{~mm}$ (11.1), $22.9 \mathrm{~mm} \mathrm{(3.2),} \mathrm{and} 10.61 \mathrm{~g}$ (0.94), respectively. In all cases, fruit were firm at maturity, elongate, and pendent and corollas were usually greenish white, characteristics associated with $C$. chinense
(D'Arcy and Eshbaugh, 1974; Eshbaugh, 1976; Smith and Heiser, 1957). Individual plants yielded one, two, three, or mixed numbers of fruits/node. However, a calyx constriction was not present on all fruits/plant or on all plants/accession. Some plants exhibited predominantly large solitary flowers that were dull white as noted by Pickersgill et al. (1979). PIs 281442 and 315018 (and others) yielded fruits that were either red or chocolate in color but were otherwise near identical in appearance, suggesting segregation for fruit color (Smith, 1950). In crosssection, the internal tissues of some chili chocolate fruit were red. The fact that this phenotype was collected from a variety of locations over a period of time suggests that it has been selected for and maintained as a distinct phenotype. Although its taxonomic classification has been questioned (Pickersgill et al., 1979), chili chocolate types are generally considered to be $C$. chinense. Hence, we opted to include these in the analyses.

The statistics on the fruit characteristics of the accessions of $C$. chinense examined are presented in Table 1. Distributions for the characters examined (fruit length, fruit width, fruit length/fruit width, and fruit weight) are presented in Figure 1A-D. Fruit length averaged $47.0 \mathrm{~mm}$ and ranged from $7.9 \mathrm{~mm}$ (PI 446904) to $113.7 \mathrm{~mm}$ (PI Grif 9269). Fruit width averaged $21.2 \mathrm{~mm}$ with a range of from $6.2 \mathrm{~mm}$ (PI 260501) to $40.0 \mathrm{~mm}$ (Grif 12450). Average fruit weight was $6.3 \mathrm{~g}$ with a range of from $0.18 \mathrm{~g}$ (PI 260504) to $22.7 \mathrm{~g}$ (PI 257136). Fruit length/width averaged 2.4 with a range from 0.8 (PI 439476) to 6.8 (PI 315031).

As indicated in Table 1 and Figure. 1A-D, the distributions of the values for mature fruit length, length/width, and weight were highly positively skewed. Assuming that selection for fruit size occurred over the course of the domestication of this species, as seems relatively certain (Eshbaugh, 1980; McLeod et al., 1982; Pickersgill, 1971), positively skewed distributions for these fruit characteristics would be expected because this was the organ subjected to selection pressure (D'Arcy and Eshbaugh, 1974). Distributions of fruit length, fruit length/width, and fruit weight failed the Kolmogorov-Smirnov test (Stuart and Ord, 1987) indicating that the distributions for those characteristics were not normal. In contrast, values for fruit width were normally distributed. Distributions for fruit length, weight, and length/width were leptokurtic as opposed to the platykurtic distribution of fruit width (Table 1).

D'Arcy and Eshbaugh (1974) noted that fruit of $C$. chinense were brown (chocolate), red, tangerine, peach, cherry, neapolitan, yellow-orange, lemon yellow, or cream. Within the materials examined in the present study, fruit were observed to be various shades of red (143), orange including tangerine (49), chocolate (20), yellow (16), and mixtures of red and orange (57), red and chocolate (12), red and yellow (11), red and cream (one), or mixtures of three or more colors (26). We observed only a single accession with cream-colored fruit, although the photographs in DeWitt and Bosland (1996) suggest that this fruit color is common in the gene pool.

Wild or primitive forms of $C$. chinense were also observed. These small, erectfruited weedy forms were described by (Pickersgill et al., 1979) and DeWitt and Bosland (1996). The relative lack of recognition afforded the primitive forms of $C$. chinense in the modern literature may be the result of the paucity of plant material available for examination or the suggestion that $C$. frutescens was the likely wild-type progenitor of $C$. chinense (Pickersgill, 1966, 1971). Pickersgill et al. (1979) recognized genuinely wild forms of the species with small, erect deciduous red fruits and a calyx constriction that were found in the Amazon River basin. Although these primitive forms had been recognized for more than 20 years, the scientific literature contains no reports of attempts to further characterize them or to further examine their relationship with the cultivated forms of $C$. chinense or with other wild or cultivated forms of Capsicum.

According to Eshbaugh (1976), all wild peppers have red fruit that are deciduous and erect. Indeed, this is typically the case and only red-fruited wild-type $C$. annuum $(C$. annuum var. glabriusculum) and wild-type C. baccatum ( $C$. baccatum var. baccatum) have been observed by RLJ. In the present study, we observed a number of smallfruited, apparently wild-type $C$. chinense with yellow (PI 260501) or orange (PI

Table 1. General statistics on four fruit parameters among 330 accessions of Capsicum chinense.

\begin{tabular}{lcccc}
\hline Statistic & $\begin{array}{c}\text { Fruit length } \\
(\mathrm{mm})\end{array}$ & $\begin{array}{c}\text { Fruit width } \\
(\mathrm{mm})\end{array}$ & $\begin{array}{c}\text { Fruit } \\
\text { wt }(\mathrm{g})\end{array}$ & $\begin{array}{c}\text { Fruit } \\
\text { length/width }\end{array}$ \\
\hline Mean & 47.035 & 21.171 & 6.311 & 2.379 \\
SD & 19.196 & 6.839 & 4.131 & 1.088 \\
SE & 1.057 & 0.376 & 0.227 & 0.059 \\
CI of mean & 2.079 & 0.741 & 0.447 & 0.118 \\
Range & 105.80 & 33.188 & 22.535 & 6.019 \\
Maximum & 113.70 & 40.000 & 22.710 & 6.830 \\
Minimum & 7.900 & 6.182 & 0.175 & 0.811 \\
Median & 44.00 & 21.275 & 5.580 & 2.129 \\
Skewness & 0.785 & 0.175 & 0.832 & 1.110 \\
Kurtosis & 0.620 & -0.513 & 0.459 & 1.404 \\
K-S distribution & $0.088^{\mathrm{z}}$ & 0.0408 & $0.095^{\mathrm{z}}$ & $0.106^{\mathrm{z}}$ \\
\hline
\end{tabular}

${ }^{\mathrm{z}}$ Failed.

CI, confidence interval; K-S, Kolmogorov-Smirnov. 

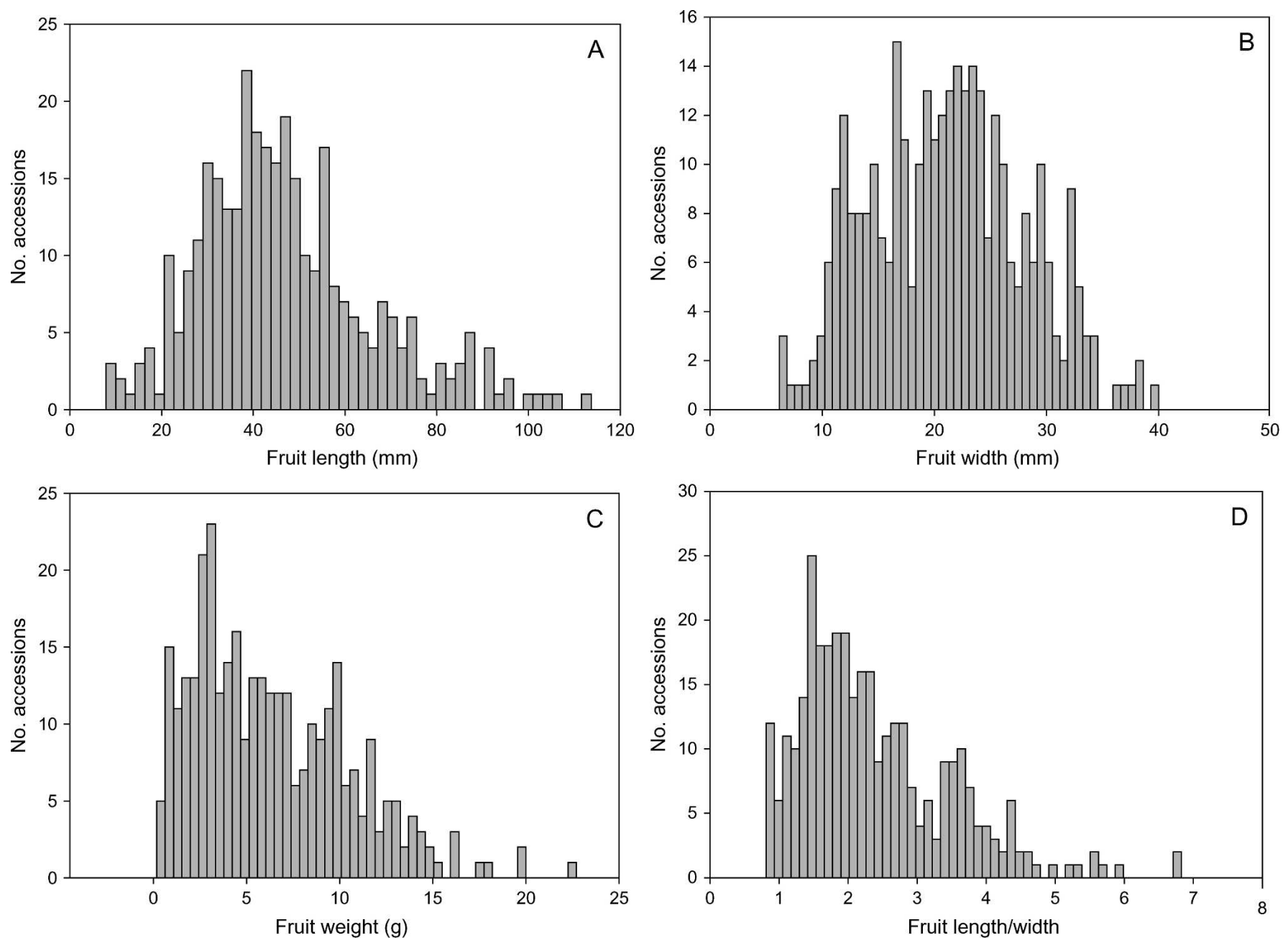

Fig. 1. Distribution of fruit length (A), width (B), weight (C), and length/width (D) values of 330 accessions of C. chinense.

260504) fruit that were small, deciduous, and erect. Although wild-type fruit are typically red, it has also been acknowledged that variation for morphological characteristics within wild taxa may range from a typical wild type to a semi- or fully domesticated form (Eshbaugh, 1976); this would include fruit color.

Small-fruited accessions such as PI 260504 were relatively rare in the collection when compared with the larger pendent forms. This may be attributable to the more defined (restricted) geographic range of these types combined with a less intense effort to collect and conserve them. The distribution of these primitive forms appears to be largely undocumented. To the author's knowledge, systematic studies that included both primitive and cultivated forms of $C$. chinense have not been conducted with the exception of Pickersgill et al. (1979). The electrophoretic studies of Jensen et al. (1979), McLeod et al. (1979), and McLeod et al. (1983) included $C$. chinense. However, no distinction was made between cultivated and wild forms. The study of Pickersgill et al. (1979) included a single wild-type $C$. chinense and a number of transitional forms. They (Pickersgill et al., 1979) noted that the wild forms of $C$. annuum, C. chinense, and C. frutescens formed an intergrading and poorly differentiated complex, which could not be readily divided into distinct taxa, whereas the domesticated forms of each taxon were clearly distinguishable from one another. This was interpreted as being suggestive of an independent allopatric domestication of the four species followed by divergence of the cultivars after domestication.

Few molecular studies have addressed the relationship between $C$. chinense phenotypes with fruit that are small, persistent, and upright and their pendent large-fruited relatives. Prince et al. (1995) used random amplified polymorphic DNAs (RAPDs) and restriction fragment length polymorphisms to examine DNA polymorphisms within Capsicum but did not address the issue of wild versus domesticated forms. RAPD markers useful in identifying individual Capsicum species were reported by Rodriguez et al. (1999). However, these were not applied to both the wild and cultivated forms. Walsh and Hoot (2001) examined phylogenetic relationships in Capsicum using DNA sequence polymorphisms in the chloroplast $a t p \mathrm{~B}-r b c \mathrm{~L}$ spacer region and the (nuclear) waxy intron. However, only a single accession of $C$. chinense was included. Toquica et al. (2003) used amplified fragment length polymorphisms to examine genetic relationships among four Capsicum sp., including 89 accessions of $C$. chinense. However, the morphological attributes of those accessions were not noted. Buso et al. (2003) used RAPDs to examine genetic differences within and among various Capsicum sp. Although 11 accessions of $C$. chinense were included, data on the primitive versus cultivated status of the materials analyzed was not provided.

Many of the characteristics that are used to define "wild-type" $C$. chinense (small, upright, small, red, and nonpersistent fruit) are essentially those same characteristics (i.e., fruit size, position, size, color, and shape) that have been previously acknowledged as being unreliable for species delimitation (Pickersgill et al., 1979). However, this does not preclude their use in describing varieties. Pickersgill (1966) and Eshbaugh (1980) recognized that the parallel development of $C$. annuum, $C$. frutescens, $C$. baccatum, and $C$. chinense would lead to erroneous conclusions regarding subspecific classification using morphological characteristics. D'Arcy and Eshbaugh (1974) suggested that different names for the cultivated and wild forms, at some taxonomic level, were clearly required. Eshbaugh (1980) suggested that 
the taxonomic logic used in distinguishing C. annuum var. annuum from $C$. annum var. glabriusculum also be applied to designate the wild ancestral and cultivated forms of C. chinense. This has yet to be done. The use of varietal epithets does provide a means to distinguish the morphological extremes of the species in terms of its fruit characteristics. However, the line between wild and semidomesticated forms and between semidomesticated and cultivated forms can be obscure. This can confound efforts to provide an accurate subspecific classification.

\section{Literature Cited}

Barboza, G.E. and L.De.Bem Bianchetti. 2005. Three new species of Capsicum (Solanaceae) and a key to the wild species from Brazil. Syst. Bot. 30:863-871.

Bosland, P.W., A.T. Bailey, and J. Iglesias-Olivas. 1996. Capsicum pepper varieties and classification. New Mexico State University, Cooperative Extension Service, Circular 530.

Buso, G.S.C., Z.P. de Sousa Amaral, L. De. Bem Bianchetti, F.B.B. Machado, and M.E. Ferreira. 2003. Genetic variability and phylogenetic analysis of Brazilian species of Capsicum. Capsicum Eggplant Newslett. 22:13-16.

D'Arcy, W.G. and W.H. Eshbaugh. 1974. New World peppers [Capsicum-Solanaceae] north of Colombia: A resume. Baileya 19:93105.

Davenport, W.A. 1970. Progress report on the domestication of Capsicum (chili peppers).

DeWitt, D. and P.W. Bosland. 1996. Peppers of the world. Ten Speed Press, Berkeley, CA.

Eshbaugh, H.W. 1980. The taxonomy of the genus Capsicum (Solanaceae). Phytologia 47:153166.

Eshbaugh, W.H. 1976. XII. Genetic and biochemical systematic studies of chili peppers (Capsicum-Solanaceae). Bull. Torey Bot. Club. 102:396-403.
Heiser, C.B., Jr. 1976. Pepper-Capsicum (Solanaceae), p. 265-268. In: Simmonds, N.W. (ed.). Evolution of crop plants. Longman, London, UK.

Heiser, C.B., Jr. and B. Pickersgill. 1969. Names for the cultivated Capsicum species (Solanaceae). Taxon 18:277-283.

Hunziker, A.T. 2001. Genera Solanacearum: The genera of the Solanaceae illustrated, arranged according to a new system. A. R. G. Gantner Verlag K.-G., Ruggell, Liechtenstein, Germany.

IPGRI. 1995. Descriptors for Capsicum (Capsicum spp.). International Plant Genetic Resources Institute, Rome, Italy.

Jarret, R.L., M. Spinks, G. Lovell, and A.G. Gillaspie. 1990. The S-9 plant germplasm collections at Griffin, GA. Diversity 6:23-25.

Jensen, R.J., M.J. McLeod, W.H. Eshbaugh, and S.I. Guttman. 1979. Numerical taxonomic analyses of allozymic variation in Capsicum (Solanaceae). Taxon 28:315-327.

McLeod, M.J., W.H. Eshbaugh, and S.I. Guttmam. 1979. A preliminary biochemical study of the genus Capsicum-Solanaceae, p. 701-713. In: Hawkes, J.G., R.N. Lester, and A.D. Skelding (eds.). The biology and taxonomy of the Solanaceae. Academic Press, New York, NY.

McLeod, M.J., S.I. Guttman, and W.H. Eshbaugh. 1982. Early evolution of chili peppers (Capsicum). Eco. Bot. 36:361-368.

McLeod, M.J., S.I. Guttman, W.H. Eshbaugh, and R. Rayle. 1983. An electrophoretic study of evolution in Capsicum (Solanaceae). Evolution Int. J. Org. Evolution 37:562-574.

Pickersgill, B. 1966. The variability and relationships of Capsicum chinense Jacq. Indiana University, Bloomington, IN. PhD Diss.

Pickersgill, B. 1971. Relationships between weedy and cultivated forms in some species of chili peppers (genus Capsicum). Evolution Int. J. Org. Evolution 25:683-691.

Pickersgill, B., C.B. Heiser, and J. McNeill. 1979. Numerical taxonomic studies on variation and domestication in some species of Capsicum, $\mathrm{p}$. 679-700. In: Hawkes, J.G., R.N. Lester, and
A.D. Skelding (eds.). The biology and taxonomy of the Solanaceae. Linn Soc. Symp. Ser. No. 7. Academic Press, London, UK.

Prince, J.P., V.K. Lackney, C. Angeles, J.R. Blauth, and M.M. Kyle. 1995. A survey of DNA polymorphism within the genus Capsicum and the fingerprinting of pepper cultivars. Genome 38:224-231.

Rodriguez, J.M., T. Berke, L. Engle, and J. Nuihuis. 1999. Variation among and within Capsicum species revealed by RAPD markers. Theor. Appl. Genet. 99:147-156.

Smith, P.G. 1950. Inheritance of brown and green fruit mature fruit color in peppers. J. Hered. 41:138-140.

Smith, P.G. and C.B. Heiser, Jr. 1957. Taxonomy of Capsicum sinense Jacq. and the geographic distribution of the cultivated Capsicum species. Bull. Torrey Bot. Club 84:413420.

Stewart, C., Jr., B.-C. Kang, K. Liu, M. Mazourek, S.L. Moore, E.Y. Yoo, B.-D. Km, I. Paran, and M.M. Jahn. 2005. The pun 1 gene for pungency in pepper encodes a putative acyltransferase. Plant J. 42:675-688.

Stuart, A. and J.K. Ord. 1987. Kendall's advanced theory of statistics. Charles Griffin and Co., London, UK.

Tewksbury, J.J., D.J. Levy, D.C. Haak, and C. Manchego. 2006. Where did the chili gets its spice? Biogeography of capsaicinoid production in ancestral wild chili species. J. Chem. Ecol. 32:547-564.

Toquica, S.P., F. Rodriguez, E. Martinez, M.C. Duque, and J. Tohme. 2003. Molecular characterization by AFLPs of Capsicum germplasm from the Amazon Department in Colombia, characterization by AFLPs of Capsicum. Genet. Res. Crop Evol. 50:639-647.

Walsh, B.M. and S.B. Hoot. 2001. Phylogenetic relationships of Capsicum (Solanaceae) using DNA sequences from two noncoding regions: The choloroplast ATPB-RBCL spacer region and nuclear waxy introns. Int. J. Plant Sci. 162:1409-1418. 